NotícIAS 



\section{Seminário 90 anos da Semana de Arte Moderna: debates}

Dando continuidade às comemorações do cinquentenário do Instituto de Estudos Brasileiros, foi realizado em abril deste ano o Seminário 90 anos da Semana de Arte Moderna: debates. O evento ocorreu no Auditório de História, na Faculdade de Filosofia, Letras e Ciências Humanas da Universidade de São Paulo e contou com vasto público. Diversos intelectuais foram convidados para compor as cinco mesas de discussão, envolvendo diferentes aspectos ligados ao modernismo brasileiro e à Semana de 1922.

\section{Programação}

17/04 às 17h00 | Conferência de abertura: Telê Ancona Lopez 18/04 às 9h | Prosa e memorialismo

Coordenação: Marcos Antonio de Moraes

Participantes: Marisa Lajolo, José Luís Jobim e Antonio Dimas

14h | Cidade, natureza e ciência

Coordenação: Jaime Tadeu Oliva

Participantes: Carlos Alberto Ferreira Martins, Lilia Moritz Schwarcz e Fraya Frehse

19/04 às 9h | Poesia modernista: A contribuição de todos os erros Coordenação: Fernando Augusto Magalhães Paixão

Participantes: Antonio Carlos Sechin, Ivan Marques e Raul Antelo

14h | As mulheres no modernismo

Coordenação: Flavia Camargo Toni

participantes: Heloisa Pontes, Maria de Lourdes Eleutério e Ana Paula Cavalcanti Simioni

20/04 às 9h | Erudita, comercial e tradicional: Debates sobre a música brasileira

Coordenação: Walter Garcia

Participantes: Paulo Castagna, Carlos Sandroni e Lincoln Antonio

14h | Patrimônio e modernismo

Coordenação: Ana Paula Cavalcanti Simioni

Participantes: Silvana Rubino, Alberto Ikeda e Márcia Chuva 
